\title{
NOTAS PARA UN ANALISIS DE LA POLITICA EDUCATIVA DE LOPEZ MICHELSEN 1974 - 1978 \\ (Primaria y Media)
}

\author{
César A. Vera Gil*
}

\section{SUMARIO}

El presente ensayo que postula lineamientos para un análisis de la Política Educativa del gobierno del doctor López Michelsen (1974-1978), en los niveles de primaria y secundaria, constituye un subproducto de la investigación "Estudio Evaluativo de la Planeación del Sector Educativo 1966-1982", que adelantó el CIUP con apoyo financiero de Colciencias. Su contenido está centrado en un seguimiento de las diversas expresiones legislativas haciendo énfasis en las relaciones entre la norma y lo postulado en el plan sectorial de desarrollo. Se aproxima también un análisis del actual proceso de renovación curricular y sobre otras medidas que en su momento suscitaron alguna polémica.

\section{ASPECTOS GENERALES DEL PLAN DE DESARROLLO}

El plan de desarrollo social económico y regional 1975-1978, tenía como objetivo central lograr un crecimiento de la economía que generara creación masiva de empleo y beneficiara "al cincuenta por ciento más pobre de la sociedad colombiana" ${ }^{70}$. Según el doctor López Michelsen desde la década de los años treinta el país había tenido planes de desarrollo que se orientaron a proporcionar "un apoyo decisivo y una alta protección al sector moderno de la economía"71. Este fenómeno había implicado descuido del sector rural y ninguna solución a los problemas de los trabajadores agrícolas sin tierra 0 minifundistas. Este modelo de desarrollo basado en el estímulo a la industrialización "también fue dejando al margen de los beneficios del crecimiento económico, y por fuera de la economía moderna, a un numeroso grupo de personas en ciudades cuya población ha aumentado a un ritmo inusitado" "72. Basado en las anteriores premisas planteó la urgencia de atenuar las desigualdades existentes entre campo y ciudad "reducir las brechas entre los barrios ricos y los barrios pobres, la brecha entre los que tienen acceso a los servicios de salud y educación, y los analfabetas y desnutridos"73. Para el logro de lo anterior la inversión pública se canalizaría prioritariamente al sector rural y a las ciudades intermedias.

Dentro de ese orden de ideas, los planes sectoriales de salud y educación serían pilares importantes en el logro de los objetivos del plan general. El postulado que orientó esta estrategia fue muy claro: "se ha considerado que, a largo plazo, la política de empleo más efectiva es dotar a la fuerza de trabajo de buena educación y buena salud con el fin de hacerla empleable"74

\footnotetext{
* Investigador CIUP. Licenciado en Historia. Universidad del Rosario. Estudios de PostgradoUniversidad Javeriana.

70 Para cerrar la brecha. Plan de Desarrollo Económico-social 1975-1978. Departamento Nacional de Planeación.

71 Ibídem P.V.

72 íbidem P.V.

73 Ibídem P.VI.

${ }^{74}$ Ibídem P.X. 
Los planes nutricionales irían en consonancia con los del sector educativo para aumentar las capacidades intelectuales de los educados. Acerca de las implicaciones de la desnutrición en el rendimiento escolar, afirmaba el plan: "Este fenómeno puede ser, precisamente la explicación de una parte sustancial de las bajas tasas de retención escolar y del hecho de que una gran masa de niños repita los primeros años de primaria" 75 . Otro de los supuestos del plan general que buscaba la integración con los planes sectoriales educativos planteaba "una apropiada política de alimentación y nutrición aumenta la productividad de las inversiones en educación, por cuanto no sólo acrecienta la capacidad de estudio y asimilación de los alumnos sino que también reduce las actuales tasas de deserción escolar"76.

Ahora bien, de acuerdo con lo enunciado en el plan general, los programas educativos para el nivel primario buscarían su universalización, con el fin de favorecer a los sectores más pobres, que como quedó dicho, representan el 500/o de nuestra población. El plan sectorial educativo tenía corno supuesto que el logro de mejores niveles educativos aumentaría la productividad de la fuerza de trabajo y en materia de financiación se planteó la necesidad de aumentar el presupuesto educativo, hasta lograr un $25 \%$ del presupuesto nacional. Esto se obtendría con la reforma tributaria utilizando los incrementos presupuestales en la construcción de treinta y dos mil aulas en el cuatrienio.

El diagnóstico sostenía que en el plano académico la carencia de investigación básica y aplicada, particularmente de investigación socio-educativa y curricular, traía como consecuencia el desconocimiento de las características culturales propias y por tanto, contenidos curriculares y métodos de enseñanza inadecuados para las necesidades de cada región.

Afirmaba al respecto que "generalmente se ha recurrido a la copia indiscriminada de métodos y técnicas de educación de otros países"77. Ante este fenómeno surgió la necesidad de fortalecer la investigación curricular.

Se formularon además políticas concretas para orientar el quehacer educativo. Podernos sintetizarlas de la siguiente manera: Se restructuraría el sector educativo en todos sus niveles y modalidades; se estimularía la participación de la comunidad en la aplicación de los programas sectoriales; se pondría en marcha un amplio plan de capacitación y perfeccionamiento docente; se evaluarían los textos escolares buscando disminuir sus costos y finalmente se fortalecería el sistema de inspección educativa con el fin de garantizar el cumplimiento de las políticas. Para combatir la alta deserción en la educación primaria se establecería el sistema de promoción automática y se adoptarían horarios y calendarios flexibles para las zonas rurales. En materia financiera se nacionalizaría el pago de la enseñanza.

\section{EXPRESIONES LEGISLATIVAS}

\section{a) La nacionalización de la enseñanza}

Una de las normas más importantes que se emitieron durante la administración López M., fue la Ley 43 del 11 de diciembre de 1975. La medida dispuso que la educación primaria y secundaria oficial sería en adelante "un servicio público a cargo de la Nación". Es decir, todos los dineros que tradicionalmente gastaban los departamentos,

\footnotetext{
${ }^{75}$ Ibídem P.110.

${ }^{76}$ Ibídem P. 111.

77 Para cerrar la brecha. Programas del sector educativo. Bogotá. Departamento Nacional de Planeación, 1975, pág. 6.
} 
intendencias y comisarías, el Distrito Especial de Bogotá y los municipios por este concepto, estarían en el futuro a cargo del fisco nacional. La ley dispuso que a partir de esa fecha la creación de nuevas plazas para maestros con cargo a la Nación se haría directamente por parte del Ministerio de Educación Nacional y redistribuyó el porcentaje que por concepto de impuesto a las ventas correspondía a cada administración regional. Igualmente, revistió al Presidente de la República de facultades por un período de doce meses, para que dictara el estatuto docente y estableciera su régimen salarial y prestacional. La medida dispuso también que las prestaciones del personal docente y administrativo causadas hasta esa fecha, estarían a cargo de las administraciones regionales. La Nación les concedía un plazo de 10 años para cancelar al Tesoro de la República el monto de dichos derechos. Así mismo, a partir de 1976 la Nación absorbería los gastos de funcionamiento por concepto de personal de la educación, inicialmente en un $20 \%$ incrementándose año por año hasta completar el 1000/o en el año de 1980.

El Ministro Durán Dussan, en la exposición de motivos al someter el proyecto a consideración de las cámaras legislativas, sostuvo que la ley buscaba aliviar los presupuestos departamentales, pues el rubro que pesaba más sobre ellos era el relativo a la educación. Sostenía que la norma era indispensable por cuanto el gobierno tenía previsto crear 43.600 nuevas plazas para el magisterio y que era urgente expedir un estatuto docente pues "la noble profesión del magisterio debía disfrutar de normas que regularan sus derechos y obligaciones de manera clara, precisa y moderna"78. En su argumentación sostuvo el Ministro que para dar cabal cumplimiento a lo postulado en el plan de desarrollo sectorial era urgente la aprobación del proyecto de ley. Esta razón la aducía en consideración a la difícil situación fiscal que vivía el sector educativo pues la crisis llegaba hasta el extremo de tener un déficit en inversión de 433 millones en el momento en el cual fue decretada la emergencia económica de 1974. Este fenómeno

—según el Ministro- no le había permitido en quince meses de gestión construir una sola aula y así lo manifestó ante la Comisión Sa. del Senado. Posterior a los debates en los que algunos senadores pidieron aclaraciones el proyecto fue aprobado. Una vez sancionada la ley, fue muy bien comentada por la prensa:

"Con la aprobación del proyecto de ley por medio del cual se nacionaliza la educación oficial, se configura una más amplia perspectiva para la democratización educacional que se contempla en los textos constitucionales, y desde el punto de vista puramente fiscal, se desarrollan afirmativamente los criterios de descentralización administrativa"79

Pero en opinión de los analistas la trascendencia de la Ley 43 ha sido muy limitada si se tiene en cuenta que desde 1960 en virtud de la Ley 111, las administraciones departamentales y municipales ya habían sido exoneradas de los gastos que originaba la educación primaria.

Más tarde, la Ley 43 fue reglamentada por Decreto 2829 de diciembre 22 de 1975 estableciendo que la creación de nuevas plazas de maestros con cargo a la Nación, sólo podrían ser autorizadas por el Ministerio de Educación, previa certificación motivada de los delegados del Ministerio ante los Fondos Educativos Regionales (FER). Es más, un parágrafo del decreto determinó que los nombramientos que se hicieran en contravención a este orden carecerían de validez.

\footnotetext{
${ }^{78}$ Política Educativa Nacional No. 5. pág. 107.

${ }^{79}$ El Tiempo, diciembre 8 de 1975. 
¿Pero qué ha sucedido en la realidad? Los gobernadores, intendentes y comisarios han continuado creando numerosas plazas, con cargo a los fiscos regionales. Al final de cuentas cuando renuncia un funcionario "su sucesor acude al Ministerio para que le ayude a solucionar el problema. El desenlace justamente llega cuando el FER de la región termina por incorporar a su nómina por orden o insinuación del Ministerio, los docentes nombrados con cargo al fisco departamental. En el estado de cosas actual no hay manera de impedir la repetición de tales abusos" ${ }^{\prime 80}$. De esta manera se incumplen las normas enderezadas a solucionar grandes problemas que afectan al sistema educativo desde hace varias décadas.

En el plano jurídico la norma ha tenido una accidentada trayectoria. En principio el Consejo de Estado la declaró constitucional sin embargo, muchos tribunales seccionales han definido a los maestros como empleados departamentales. Los fallos regionales han sido recibidos con beneplácito por parte de las agremiaciones docentes las cuales afirman que los veredictos los favorecen por cuanto las prestaciones asistenciales y legales son significativamente mejores que las percibidas en los planteles nacionales.

En síntesis la única parte de la ley que ha surtido los efectos previstos, es la relativa a la redistribución del porcentaje del impuesto a las ventas que se destina al rubro educativo. En su balance de diecinueve meses de gestión frente al Ministerio de Educación el doctor Durán Dussan al referirse a la norma la calificó ingenuamente como "una de las reformas educativas más amplias y más importantes de toda la historia colombiana" 81 .

Sin embargo en eventos recientes sobre la problemática educativa en las cuales han participado los gremios docentes e incluso los ministros de educación, se ha puesto en tela de juicio la efectividad y aplicación de la Ley 43. Para los gremios del magisterio la medida no ha tenido ninguna efectividad y por el contrario ha creado un caos en la financiación de la educación pública. Consideran como razón primordial de este caos la insuficiencia del situado fiscal para asumir los gastos de la educación primaria y media del sector oficial.

El Estado por su parte ha reconocido las inconsistencias e inoperancia de la nacionalización: "en 1975 se expidió la ley que nacionalizó el costo de la educación primaria y secundaria, pero como se sabe, los docentes siguieron a cargo de las regiones, con lo cual se operó una extraña e ineficiente dualidad de patronos, que es en parte el origen de los complejos problemas que se han presentado desde entonces" ${ }^{2}$. Además de ello "a partir de la ley de nacionalización se ha operado una falta de claridad sobre las funciones que debe cumplir al nivel nacional y regional. No están claros ni definidos aspectos como la evaluación y el control del proceso educativo o la responsabilidad por una serie de medidas administrativas"'4. Ante tal situación la Ministra Eder de Zambrano, sometió a con-

sideracíón de las Cámaras Legislativas un proyecto de ley de descentralización conocido como SE, que en su momento fue cuestionado por Fecode y archivado por inconveniente y lesivo a los intereses del magisterio.

\footnotetext{
${ }^{80}$ Rodrigo Lozada y Hernando Gómez B. Problemas Administrativos y Presupuestales de la Educación Primaria Oficial. Ensayo publicado en: Revista Colombiana de Educación No. 8. p. 130.

${ }^{81}$ Política Educativa Nacional No. 5, p. 219.

82 Eder de Zambrano, Doris. "El Ministerio frente a la crisis de la Educación Pública". Publicado en Revista “Educación y Cultura" No. 2. Bogotá, CEID 1984, p. 20. 


\section{b) La reestructuración del sector educativo}

El plan sectorial del gobierno de López Michelsen, teniendo en cuenta los objetivos para la educación primaria (énfasis en las áreas rurales, promoción automática, mejoramiento de la calidad de la enseñanza, universalización o incrementos presupuestales) planteó como una de las principales políticas la de "reestructurar el sistema educativo en sus diferentes niveles y modalidades, en busca de una mayor coherencia interna y de la adecuación de los programas al contexto socio-económico y características de los educandos"83.

La restructuración anunciada en el plan se implementó en virtud del Decreto No. 088 de 1976. La medida organizó el sistema educativo en cuatro niveles: educación ureescolar, educación básica, (primaria y secundaria) educación media e interrnedia y educación superior. La educación básica compuesta por cinco grados de primaria y cuatro de secundaria, se impartiría a la población escolar a partir de los 6 años de edad, y orientaría la vocación de los alumnos. Los cinco grados de primaria serían obligatorios y gratuitos en las escuelas del Estado. El Artículo ${ }^{84}$, definió la educación como un "servicio público en cumplimiento de una función social".

La disposición también reorganizó administrativamente el Ministerio de Educación Nacional, definió las entidades constitutivas del sector educativo, las funciones de sus diversas secciones, su estructura y organización y suprimió algunos institutos.

Ahora bien, las funciones primordiales del Ministerio serían: "garantizar la libertad de enseñanza, ejercer la inspección y vigilancia de los institutos docentes públicos y privados. Adoptar la política nacional en materia de educación, ciencia y cultura en concordancia con los planes generales de desarrollo. Formular los criterios y las normas que deban orientar el desarrollo de la educación pública en todo el territorio nacional. Elaborar conjuntamente con el Departamento Nacional de Planeación los planes y programas de desarrollo de los servicios educativos y culturales" 85

La estructura del Ministerio quedó a partir de la fecha de la siguiente manera: Despacho del Ministro, Unidades de Dirección, Unidades de Asesoría adscritos al despacho del Ministro, Unidades de Ejecución y Control a saber: Dirección General de Capacitación y Perfeccionamiento Docente Currículo y Medios Educativos y Dirección General de Servicios Administrativos. La medida señaló las funciones de todas y cada una de las dependencias.

El Artículo 45 ordenó la supresión del Instituto Colombiano de Pedagogía -ICOLPE, asignando las tareas de investigación educativa a la Universidad Pedagógica Nacional. El personal que venía laborando en dicha Institución se trasladaría al Ministerio de Educación para las tareas de capacitación y perfeccionamiento docente, y a la Universidad Pedagógica Nacional para los programas de investigación. Igualmente, el Artículo 46 ordenó la supresión de la Subgerencia Pedagógica del Instituto Colombiano de Construcciones Escolares - ICCE-, la cual venía administrando los Institutos Nacionales de Educación Media —INEM- y los Institutos Técnicos Agrícolas - ITAS- El personal docente y administrativo de estos Centros Docentes sería incorporado sin necesidad de nuevo nombramiento a la nómina del Ministerio de Educación Nacional. A partir de

\footnotetext{
83 íbidem, p. 21.

${ }^{84}$ Para cerrar la brecha, Programa del Sector Educativo. Departamento Nacional de Planeación. Bogotá, 1975, pág. 10.

${ }^{85}$ Articulo 16. Decreto 088 de 1976.

Digitalizado por RED ACADEMICA
} 
aquella fecha la administración de los INEM y los ITAS estaría a cargo exclusivamente de la División Especial de Enseñanza Media Diversificada.

Es evidente que a partir del año 1976 el Ministerio de Educación dejó de ser simplemente una entidad administradora y fiscalizadora del quehacer educativo. Aparte de esto garantizaría la libertad de enseñanza, adoptaría la política educativa nacional, elaboraría y experimentaría los programas oficiales, reglamentaría e inspeccionaría los planteles privados y desarrollaría el proceso de planeación educativa en concordancia con el plan general.

El Decreto 088 sin duda representó una significativa reforma del sector educativo, pues lo unificó y lo hizo coherente con otras instancias del Estado. Sin embargo, la norma fue cuestionada por la prensa conservadora que afirmó:

"Nada nos ganamos con excelentes textos jurídicos cuando hay un abismo entre la legislación y la realidad (...). No ha habido un plan serio de educación primaria. Simplemente se construyen escuelas y se nombran maestros, algunas veces donde no hay población. Se tiene el criterio de un avance cuantitativo hasta donde sea posible, pero se acepta la hipótesis de que es una utopía la universalización de la enseñanza"86.

\section{c) La reforma curricular}

El diagnóstico del plan sectorial del gobierno del "Mandato Claro", al referirse a las relaciones escuela-comunidad, sostuvo que: "En muchos casos la escuela no se ha integrado a la comunidad y su acción se ha limitado al proceso rutinario de enseñar contenidos escogidos para realidades muy diferentes a las que circundan a la escuela y sin ninguna relación con los otros servicios que reciben las comunidades de la región" ${ }^{87}$. Como una alternativa para corregir ese desfase, se planteó la necesidad de emprender un plan de "Mejoramiento Cualitativo de la Educación", que bus-cara el incremento de la matrícula, el nombramiento de maestros y la construcción de escuelas, además una reestructuración curricular que adecuara los contenidos a las necesidades regionales, utilizará la tecnología educativa* y que vinculará la comunidad a la escuela.

Una de las expresiones legislativas que orientaron el proceso de renovación curricular en el marco del "Mejoramiento Cualitativo de la Educación" fue el Decreto 1419 de 1978. El artículo primero estableció que se entendería por currículo "el conjunto planeado y organizado de actividades, en el que participan alumnos, maestros y comunidad para el logro de los fines y objetivos de la educación". Acerca de los fines del sistema educativo estableció once puntos fundamentales. Los más interesantes quizás: el sexto que busca "desarrollar en la persona la capacidad crítica y analítica del espíritu científico, mediante el proceso de adquisición de los principios y métodos en cada una de las áreas del conocimiento, para que participe en la búsqueda de alternativas de solución a los problemas nacionales". El séptimo no sería menos importante, puesto que estaría encaminado a "promover en la persona la capacidad de crear, adoptar y transferir la tecnología que se requiere en los procesos de desarrollo del país".

\footnotetext{
${ }^{86}$ El Siglo. marzo 14 de 1976, Página Editorial.

${ }^{87}$ Para cerrar la brecha. Programas del Sector Educativo, p. 6.
}

*Dentro de ese marco se concebía la Tecnología Educativa como "La aplicación del conocimiento mediante un enfoque científico, sistemático e interdisciplinario para dar solución a los problemas educativos, con el objeto de optimizar la operación del sistema educativo en todos los niveles". 
Respecto a las características generales de los currículos deberían estar "centrados en el alumno, mantener el equilibrio entre la conceptualización teórica y la aplicación práctica del conocimiento, constituir un sistema dinámico que concurra a la formación personal y a la integración social y particularmente en el currículo de educación preescolar y básica primaria el proceso educativo se haría en forma integrada y se iniciaría la orientación vocacional" ${ }^{8}$.

La renovación curricular que se inició a partir de 1978 en los Departamentos de Nariño y Valle dentro del plan de "Mejoramiento Cualitativo", ha tenido serios reparos por parte de diversos sectores interesados en la problemática educativa nacional. En numerosos foros y demás eventos académicos se ha cuestionado la concepción filosófica y pedagógica que los inspira. Respecto a la orientación de los programas se les ha criticado su inspiración Taylorista que pretende identificar el proceso enseñanza-aprendizaje, con el proceso de producción en una fábrica.

Con la implantación del Diseño Instruccional (DI) — según los analistas— el maestro se limita a su aplicación teniendo en cuenta unos objetivos y unas actividades, convirtiéndose así en un simple "Administrador de Currículo" un "Embutjdor de Contenidos". Esto ha traído como consecuencia la implantación de una pedagogía tecnicista ${ }^{89}$ que desconoce al maestro como un agente cultural y lo limita a la aplicación de una especie de recetario de manera mecánica y totalmente acrítica. Lo único que debe interesarle es el logro de los resultados preestablecidos por los "Técnicos Programadores", el maestro es un simple ejecutor de programas, Sobre las implicaciones de estos modelos pedagógicos comenta un autor: "Pensar el problema de la educación en términos de una eficiencia exterior que nos la presenta como un sistema estructurado con el fin de obtener determinados resultados preestablecidos, significa hipotecar la vida en la escuela a un objetivo que le es ajeno. Es la experiencia misma, a lo largo de un período definitivo de la existencia, el período de la socialización de los individuos en la escuela, lo que está en juego" 90 .

La oposición a la reforma curricular no ha sido únicamente un movimiento contestatario a una política del Estado, sino el producto de reflexiones y análisis sobre la realidad educativa colombiana, sobre la pedagogía, sobre la cultura y sobre el maestro como intelectual que no solamente transmite unos conocimientos sino que además forma ciudadanos para una sociedad. Fenómenos de reciente aparición como el movimiento pedagógico $^{91}$, impulsado por los gremios docentes, que busca superar el estrecho marco

\footnotetext{
${ }^{88}$ Caro, Miguel Antonio. "El Código del Educador", pág. 731.

89 "A partir del presupuesto de neutralidad científica e inspirada en los principios de racionalidad, eficiencia y productividad, esa pedagogía propone el reordenamiento del proceso educativo de manera de tornarlo objetivo y operacional. De modo semejante a lo que ocurrió con el trabajo fabril, se pretende la objetivación del trabajo pedagógico". Tomado de: "Las teorías de la educación y el problema de la marginalidad en América Latina". Ensayo publicado en: Revista Colombiana de Educación No. 13. Bogotá, 1984, pág. 15. ${ }^{90}$ Hernández, Carlos Augusto. La Reforma Curricular: Cíentificismo y Taylorización. Revista Educación y Cultura No. 2, Bogotá, CEID, 1984, pág. 38

${ }^{91}$ Es importante reseñar brevemente las metas y la filosofía del movimiento pedagógico: "El movimiento pedagógico busca crear una corriente de pensamiento y acción en el campo de la cultura y específicamente en la educación y la pedagogía, no busca solamente la transformación de las prácticas pedagógicas en el salón, no es un movimiento por la didáctica, es un movimiento que reivindica toda la condición del maestro como la del niño, la del joven y la de la escuela". Sobre la escuela y la cultura se plantea, "si los fenómenos culturales me crean por fuera de la escuela, ésta tiene la posibilidad de ser el espacio de encuentro y de síntesis de la vida cultural de municipios y provincias, desde donde se pulsarían y expresarían las necesidades particulares de cada región. La escuela se convertiría en lugar de confluencia de todo tipo de tradiciones orales y quehaceres, de diversos saberes no académicos, de manifestaciones artísticas 
de la lucha puramente reivindicativa frente al Estado y rescatar al maestro como un trabajador de la cultura y a la pedagogía como una ciencia, han permitido que prospere la imagen secular de la profesión docente y se abra un espacio de reflexión y análisis de nuestra realidad educativa.

El proceso apenas se ha iniciado es cierto y hay mucho camino por recorrer para que logremos otra escuela y otros maestros. Como lo señala un investigador "La reflexión crítica hará que se reconozca cuál es el papel de la experiencia y abrirá el camino al diálogo de esta experiencia con los Saberes sistemáticos ligados a la práctica educativa. Las relaciones entre ciencia y pedagogía deben ser discutidas"92. Lo anterior conducirá sin duda, a que los diversos agentes educativos presenten alternativas frente a los múltiples problemas que aquejan a la educación en todos sus niveles.

\section{e) Reestructuración de la educación media}

En los objetivos del plan de desarrollo sectorial del gobierno del doctor López $\mathrm{M}$. se planteó la necesidad de reestructurar la educación media "aprovechando la experiencia en enseñanza diversificada de los Institutos Nacionales de Educación Media93, de los Institutos Técnicos Agrícolas y de las concentraciones de Desarrollo Rural para ofrecer carreras intermedias" $"$. Se previó además la construcción y dotación de 200 planteles de doble jornada para 300.000 estudiantes, creación e incremento de jornadas adicionales en centros educativos oficiales y privados; ampliación y fortalecimiento del bachillerato radial; incremento de becas a través del ICETEX, reestructuración de los currículos de los Institutos de Enseñanza Media Diversificada (INEM) y de los Institutos de orientación vocacional para hacerlos más acordes a las necesidades de recursos humanos del país. La reforma curricular de la educación media diversificada permitiría "una acción intensiva para establecer carreras intermedias, superando el bachillerato enciclopedista y adecuar el sistema educativo a la demanda de la economía nacional" ${ }^{95}$. Meta que encajaba dentro de las del plan general que buscaban una ampliación del empleo y la cualificación de la fuerza de trabajo.

Para dar cumplimiento a ese aspecto del plan, el Ministerio de Educación emitió la Resolución No. 130 del 23 de enero de 1978. Mediante esta norma se reestructuraron los programas de estudios de los Institutos de Enseñanza Media Diversificada (INEM) y de los Institutos Técnicos Agrícolas (ITAS). La disposición acogió las recomendaciones derivadas de las evaluaciones realizadas durante el proceso de experimentación. En virtud de lo anterior se determinó que los grados sexto y séptimo de la enseñanza básica secundaria equivaldrían a la etapa de exploración vocacional, la cual permitiría al estudiante elegir entre cinco áreas: académica, agropecuaria, comercial, industrial y promoción social. Los dos grados restantes (octavo y noveno) serían de orientación vocacional y las áreas ofrecerían las siguientes modalidades:

Área Académica: Modalidad Ciencias

Modalidad Humanidades

Área Agropecuaria: Modalidad Secretariado Modalidad Contabilidad

populares, en fin, de la vida misma de vastos espacios". Tomado de: Movimiento Pedagógico: otra escuela otros maestros. Revista Educación y Cultura No. 1. Bogotá, Julio de 1984, p.p. 10 y s.s.

${ }_{92}$ Hernández, Carlos A. Op. cit., pág. 41

${ }^{93}$ El sistema de Institutos de Enseñanza Media Diversificada INEM fue implantado en Colombia mediante el Decreto 1962 de 1969 durante la presidencia del doctor Carlos Lleras R. Más tarde el Decreto 060 del 22 de enero de 1974, dividió el bachillerato en dos ciclos. El primero denominado básico con una duración de 4 años, sería común para todos los estudiantes. El segundo denominado vocacional de 2 años ofrecía las siguientes opciones: Bachillerato académico, pedagógico o formación normalista, industrial, comercial, agropecuario y promoción social.

${ }_{94}$ Departamento Nacional de Planeación. Op. Cit. pág. 9.

95 Ibídem, pág. 11. 
Área Industrial:

Modalidad Metalmecánica

Modalidad Electricidad y Electrónica

Modalidad Química Industrial

Modalidad Construcción

Área Promoción Social: Modalidad Desarrollo de la Comunidad ${ }^{96}$

De otro lado, el Ciclo de Educación Media Vocacional lo constituirían los grados décimo y undécimo. De acuerdo con cada área específica, la intensidad horaria sería más rigurosa en las materias afines con la modalidad correspondiente. Según el artículo 7o. "la dirección y el seguimiento de la experimentación del nuevo currículo estaría bajo la responsabilidad del Ministerio de Educación Nacional".

La adopción de estas modificaciones curriculares evidenciaron una tendencia clara de la política educativa de López: la educación media no debía programarse únicamente con la mira de producir bachilleres que continuaran una carrera universitaria, sino con el fin de formar técnicos de nivel intermedio cristalizándose así uno de los postulados de su plan de desarrollo sectorial. Los recursos humanos del país no podían estar aislados de los requerimientos del sistema productivo.

También es importante destacar, que si bien se hacía énfasis en las modalidades técnicas no se descuidaron las humanidades. Para completar los ajustes académicos, el Ministerio de Educación dictó la Resolución 4336 del 13 de abril de 1978. La norma ordenó que la transferencia de estudiantes de los INEM y los ITAS, al resto de planteles oficiales y privados del país se haría sin necesidad de sorneterse a examen de admisión, validación o nivelación. Esta transferencia se autorizaría en dos casos: para continuación de estudios en la misma modalidad; o en otra diferente y para continuar cualquier modalidad, si había cursado y aprobado los dos años de educación básica secundaria. La resolución facilitaría enormemente el cambio de plantel bien fuera por voluntad del estudiante o por traslado de su lugar de residencia, lo que permitiría evitar su deserción.

En el terreno de la evaluación del aprendizaje y la promoción de estudiantes de Educación Media - en todas las modalidades-se expidió la Resolución No. 1852 del 3 de marzo de 1978. En ella se definieron los objetivos del proceso de evaluación, los períodos de trabajo escolar, las escalas de calificación y las condiciones de aprobación o reprobación de un curso. En adelante se calificaría en una escala de 1 a 10, teniéndose como mínima nota para aprobación de cada asignatura la calificación de 6 . Los aspectos evaluables del aprendizaje serían:

a) Los conocimientos, teóricos y prácticos.

b) Las habilidades y destrezas.

c) Los valores y actitudes.

El trabajo escolar estaría dividido en cuatro períodos que significarían cada uno el $20 \%$ de la nota final, una evaluación intermedia y una evaluación final que representaría el $10 \%$ respectivamente. Se consideraría reprobado un curso cuando el alumno perdiera 3 o más asignaturas. En el caso de pérdida de una o dos asignaturas, el alumno tendría derecho a habilitarlas.

\footnotetext{
${ }^{96}$ Artículo 1o. de la resolución No. 130 de 1978. Tomado de "Política Educativa Nacional No. 9, pág. 7. Bogotá, 1980.
} 
La norma unificó y actualizó los sistemas de evaluación y puso fin al desorden que existía raíz de las contradictorias interpretaciones que se dieron a una Resolución similar expedida por el gobierno anterior (Resolución 2109 de 1974).

\section{e) Las jornadas adicionales}

Recién inaugurado, el gobierno emitió el Decreto No. 2112 del 3 de octubre de 1974. En virtud de esta medida quedaron congelados los derechos de matrículas y pensiones que tuvieran establecidos los planteles de educación primaria, media y superior, de carácter oficial o privado. El Artículo 5o. contemplaba sanciones para las instituciones que violaran la determinación. La norma no fue ciertamente bien recibida por parte del sector privado que comenzó a ejercer presiones para que fuera modificada o derogada. Las asociaciones de educadores privados y de comunidades religiosas dirigieron un mensaje al Presidente López, donde le planteaban la crisis de recursos que supondría la congelación de matrículas y pensiones. Para dar respuesta se optó por nombrar una comisión de estudio para que presentara alternativas de solución, compuesta por representantes del Ministerio de Educación Nacional y el sector privado. Dos meses más tarde con base en los Acuerdos de esta comisión, el gobierno expidió el Decreto No. 2854 del 26 de diciembre ${ }^{97}$ de 1974. El Decreto se inspiraba en la premisa de "Que los sectores oficial y privado deben trabajar con una misma finalidad social en las actividades educativas para beneficio de la niñez y de la juventud con menos capacidad económica". Esta concertación dio como resultado el establecimiento de segundas jornadas (posteriormente conocidas como adicionales) en los colegios oficiales y privados.

Para la creación de estas jornadas en los planteles particulares, el Estado proporcionaría el personal docente necesario y el colegio respectivo su capacidad instalada. Los estudiantes que fueran admitidos en las jornadas adicionales cancelarían sus derechos de matrícula y pensión con el mismo procedimiento de los colegios oficiales, es decir, de acuerdo con el monto de renta gravable del padre de familia. La creación de la jornada adicional daría derecho automáticamente al plantel, para reajustar las matrículas y pensiones hasta un $20 \%$ en la jornada ordinaria.

Por otra parte, los colegios particulares que no establecieran jornadas adicionales estaban obligados a asignar hasta un $30 \%$ de becas, para que les fuera autorizado el reajuste de pensiones.

La prensa liberal expresó así su beneplácito por el acuerdo entre los sectores público y privado de la educación:

"A través de este acuerdo, cuyos vastos alcances quizá aún no han sido bien comprendidos por la mayoría de la opinión, la educación privada tan calumniada en ocasiones por comentaristas carentes de información, ha hecho evidente una vez más, su propósito de servir en forma eficiente a la elevación del nivel cultural de nuestro pueblo (...). Las jornadas populares serán sin duda un interesante experimento, a cuyo éxito todo el país debe colaborar"98.

La prensa conservadora no tan elogiosa y optimista así se manifestó:

\footnotetext{
${ }^{97}$ Este Decreto fue complementado por la Resolución No. 530 del 18 de febrero de 1975, el Decreto 2450 de noviembre 17 del mismo año y el Decreto 1668 del 16 de diciembre de 1976.

${ }^{98}$ El Tiempo, diciembre 16 de 1974. 
"El actual problema de las jornadas escolares no se soluciona conquistando una gran cantidad de interesados aplausos, sino en la segura obtención de resultados culturales y educativos beneficiosos para el país y especialmente para el elemento humano. Pero las jornadas continuas y populares no tienen esta finalidad sino única y expresamente la de distraer la opinión pública con la cantidad pero no con la calidad"99.

Ahora bien, en el plano de las realizaciones, el programa de jornadas adicionales ha cumplido sus objetivos en mínima proporción. Según evaluación realizada por técnicos del Ministerio de Educación la jornada adicional fue establecida apenas en 443 planteles en todo el territorio nacional. "No ha representado un aumento considerable de cupos (en 1977 representó escasamente el $2.81 \%$ del total de la matrícula en educación media del país), acusa permanentes déficit presupuestales, respecto al personal docente éste es objeto de sobrecarga académica y sus salarios no les son cancelados oportunamente" ${ }^{\prime 100}$. Los resultados del programa han sido tan modestos, que los gremios del magisterio han propuesto reiteradamente al Estado que suprima las jornadas adicionales existentes en colegios privados y asimile su personal docente en los planteles oficiales.

\section{Una polémica medida}

En las postrimerías de su gobierno (julio 27/78) el doctor López y su Ministro de Educación, Rivas Posada, emitieron el Decreto más polémico de toda su administración el No. 1543. Mediante esta disposición, se establecieron los requisitos para los planteles que aspiraban a obtener licencia de iniciación de labores, o aprobación de estudios. También se ordenó la inscripción de los establecimientos de educación formal y se reglamentó lo relativo a la expedición de certificados.

El artículo que dio origen a la oposición del sector privado, fue el quinto que estatuyó tajantemente:

"A partir de la vigencia del presente decreto sólo puede otorgarse licencia de iniciación de labores y aprobación de estudios a los establecimientos educativos no oficiales de los niveles de preescolar, básica primaría, básica secundaria, media vocacional e intermedia profesional, que estén constituidos como personas jurídicas sin ánimo de lucro (fundaciones, asociaciones o Corporaciones Civiles, Instituciones de utilidad común) o cooperativas".

Este intento de controlar el enriquecimiento de particulares en virtud de la creación de instituciones educativas, fue inmediatamente condenado por considerarse como un obstáculo a la iniciativa privada y como expreSión de un excesivo intervencionismo del Estado. Uno de los primeros en criticar la medida fue el economista liberal Hernán Echavarría Olózaga quien comentó:

"El decreto que trata de limitar la actividad privada en la educación es un esperpento en todo sentido (...). Es deber del Estado suministrar a todos los ciudadanos educación adecuada. Eso no se discute. Pero si el Estado, en la práctica y a ojos vistos, no es administrativamente capaz de prestar este servicio, no debe pretender impedir que lo presten los particulares" ${ }^{\prime 101}$.

\footnotetext{
${ }^{99}$ El Siglo, abril 13 de 1975.

${ }^{100}$ Evaluación de Jornadas Adicionales en: Revista Colombiana de Educación No. 2. pág. 125. Bogota. CIUP, 1978.
}

${ }^{101}$ El Tiempo, agosto 8 de 1978. 
Como es evidente, la oposición a la medida se enmarcaba dentro de una lógica irrebatible para el Estado, y que había sido hábilmente definida por la Asociación de Colegios Privados: "Si el Estado garantiza la educación gratuita para todos los colombianos, la educación privada ha dejado de cumplir su función”.

Por su parte la prensa conservadora hacía las siguientes observaciones al interés del gobierno por controlar la educación privada:

"Los colegios-negocio prácticamente no existen. El gobierno se encarga de que no sean rentables con el control de pensiones y la falta de estímulos. Dar buena educación es muy costoso pues se requieren instalaciones y dotaciones que exigen grandes inversiones. A los profesores se les deben pagar doce meses de sueldo mientras los alumnos sólo pagan diez meses. Basta con repasar la lista de educadores, con colegios privados para comprobar que han gastado sus vidas sin compensación económica" 102

En el plano jurídico se sostenía que el Decreto 1543 era violatorio de los Artículos 30, 32, 39 y 41 de la Constitución que consagraban y garantizaban respectivamente: la propiedad privada, la libertad de empresa, la libertad de escoger profesión u oficio y la libertad de enseñanza. Ante el cúmulo de objeciones y ataques el Ministro Rivas Posada se vio precisado a defender así el Decreto:

"Educar no es ni puede ser lo mismo, aun dentro de nuestro sistema económico, de libre empresa y de mercado, como cultivar repollos o tener una fábrica de muebles"103.

Así las cosas, la instancia legal que debía dirimir el conflicto sería el Consejo de Estado. Finalmente triunfaron los argumentos del sector privado, cuando por auto del 21 de septiembre de 1978 emanado de la Sala de lo Contencioso Administrativo, se suspendió el controvertido Artículo 5o. Naufragaba así otro intento por controlar el aumento de los costos educativos, fenómeno que representaba sistemáticamente un dique para lograr aunque sea en mínima parte una democratización auténtica de la enseñanza media, la cual se encuentra actualmente aproximadamente el $70 \%$ en manos del sector privado.

\section{CONCLUSION}

Vista en su conjunto la política educativa del gobierno de López Michelsen en educación primaria se orientó básicamente al logro del "Mejoramiento cualitativo" pues se partió de la premisa de que la expansión cuantitativa experimentada por el aparato escolar desde la segunda mitad del Frente Nacional, urgía un replanteamiento de la concepción del fenómeno educativo como un problema de cupos. Errada o no, dicha política tuvo su expresión más elocuente en el proceso de renovación curricular que ha originado un interesante debate pedagógico y epistemológico, que está lejos de dirimirse.

Ahora bien, en materia de educación secundaria y media vocacional, con el fin de lograr el viejo anhelo de "un currículo para la enseñanza diversificada acorde con las necesidades de recursos humanos del país", el gobierno de López modificó

\footnotetext{
${ }^{102}$ El Siglo, agosto 10 de 1978.

${ }^{103}$ El Tiempo, agosto 3 de 1978. 
sustancialmente los planes y programas de los INEM y los ITA. Además de estas reestructuraciones académicas se establecieron otras de índole administrativa que se reflejaron positivamente en la enseñanza media vocacional.

Otro aspecto relevante y polémico fue el relacionado con la nacionalización de la enseñanza, la cual ha sido objeto de eruditos estudios sobre economía de la educación y permanente motivo de preocupación de los gremios docentes.

De otra parte, visto globalmente el plan "Para cerrar la brecha" ha sido uno de los más coherentes y bien estructurados de los últimos gobiernos. En opinión de Urrutia este plan "inició una nueva etapa de la planeación en el país. El plan pone muy poco énfasis en los modelos macro-económicos formales y plantea exclusivamente un conjunto bastante completo de políticas. Se hace un esfuerzo importante por hacer dichas recomendaciones de políticas muy explícitas y congruentes entre sí, Un objetivo principal del plan era lograr que todas las entidades estatales siguieran políticas congruentes" ${ }^{104}$. Por esta causa, en la presente aproximación al análisis del plan sectorial educativo (en primaria y secundaria), fue necesario hacer constante referencia a las políticas que lo orientaron. No se podía hablar de planeación educativa exclusivamente, sino de políticas educativas y expresiones legislativas de las mismas.

\section{BIBLIOGRAFIA}

ARNOVE, Robert. Políticas Educativas durante el Frente Nacional. Revista Colombiana de Educación No. 1. Bogotá, 1978.

CARO, Miguel Antonio. El Código del Educador. Bogotá, 1978.

DEPARTAMENTO NACIONAL DE PLANEACION. Para cerrar la brecha. Programas del Sector Educativo. Bogotá, 1975.

DURAN, Dussan, Hernando. Memoria al Congreso Nacional. Bogotá. Ministerio de Educación Nacional, 1978.

EDER de Zambrano, Doris. El Ministerio frente a la crisis de la educación pública. Publicado en Revista "Educación y Cultura" No. 2. Bogotá, CEID, 1984.

EL SIGLO. Artículos y Editoriales, 1975-1978.

EL TIEMPO. Artículos y Editoriales, 1975-1978.

HERNANDEZ, Carlos Augusto. La Reforma Curricular: Cientificismo y Taylorización. En: Educación y Cultura No. 2. Bogotá. CEID, 1984.

LOPEZ Michelsen, Alfonso. El Gobierno del Mandato Claro. Tomo II. Imprenta Nacional, febrero 1976.

MINISTERIO DE EDUCACION NACIONAL. Política Educativa Nacional. Serie del Educador. Nos. 5, 6, 7, 8 y 9.

\footnotetext{
${ }^{104}$ Urrutia Montoya, Miguel. "Teoría y Realidad de la Planeación en Colombia". Revista de Planeación y

Desarrollo. Volumen XV. No. 4, pág. 3. 
PARRA Sandoval, Rodrigo. Estudios Sociales sobre el Maestro colombiano. Revista Colombiana de Educación No. 4. Bogotá, 1979.

ROJAS, Felipe y otro. Movimiento pedagógico, otra escuela otros maestros. Revista Educación y Cultura No. 1. Bogotá, CEID, 1984.

SAVIANI, Dermal. Las Teorías de la Educación y el Problema de la marginalidad en América Latina. Revista Colombiana de Educación No. 13. Bogotá, 1984.

VASCO, Carlos Eduardo. Conversación informal sobre la reforma curricular. Revista Educación y Cultura. No. 4, Bogotá, CEID, 1985. 